\title{
Review of Studies Reporting the Incidence of Acute Type B Aortic Dissection
}

\author{
Marcus Brooks \\ North Bristol NHS Trust, Southmead Road, Westbury-on-Trym, Bristol BS10 5NB, UK; \\ marcus.brooks@nbt.nhs.uk
}

Received: 27 June 2020; Accepted: 28 October 2020; Published: 10 November 2020

\begin{abstract}
Aortic dissection (AD) causes more deaths each year in the United Kingdom than road traffic collisions. Yet the incidence of AD is not known. The management of acute type B AD (TBAD) is changing, with the greater use of thoracic aortic stent grafts (TEVAR) in treatment and fewer open surgical procedures performed. The study's aim is to review the worldwide, English language published, literature on acute TBAD incidence and treatment, to report on its strengths and limitations, and better understand changes in incidence over time and between countries. Thirty-one studies were identified that focus on the epidemiology and treatment of TBAD. Eight of these studies report the incidence of acute TBAD as between of $0.5-6.3$ per 100,000 person years. Hospital admissions for aortic dissection are reported to be increasing in six studies and stable in one study. The proportion of patients with TBAD operated on varies between studies (range 13\% to 76\%). Studies identify patient age (median 51-77 years), gender (range $48 \%-81 \%$ male) and prevalence of cardio-vascular risk factors, specifically hypertension, in the populations studied as independent factors influencing aortic dissection incidence. Treatment of acute TBAD remains largely conservative with analgesia, hypertension control and serial cross-sectional imaging (range 24\%-87\% TBAD medically treated). The use of TEVAR to treat acute AD is increasing worldwide (range $13 \%-76 \%$ TBAD treated with TEVAR). The incidence of TBAD is under-reported due to out of hospital deaths, variable clinical presentation (miss-diagnosis) and coding errors. Importantly for research, the single International Classification of Diseases (ICD) code for aortic dissection, I17.0, does not distinguish between acute, chronic, type A or type B dissection types. Similarly, the OPCS Classification of Interventions and Procedures version 4 (OPCS-4) codes for TEVAR, L27.4 and L28.4, do not distinguish between acute and chronic AD presentation, unlike the codes for open thoracic aortic replacement. Standardised reporting of aortic dissection type, and the urgency of both the initial presentation (acute or chronic) and treatment (emergency, urgent or planned) in future studies would allow more meaningful comparisons between populations.
\end{abstract}

Keywords: aortic dissection; epidemiology; incidence; thoracic aortic stent graft

\section{Introduction}

In 2013, Howard et al. reported that the incidence of acute aortic dissection (AD) in the United Kingdom was increasing. They postulated that this was in a large part due to population aging, and that incidence of acute type B AD (TBAD) could overtake that of ruptured abdominal aortic aneurysm (AAA) by 2030 [1]. In 2017, Bottle et al. reported wide regional variation across English cardiac centres in rates of both diagnosis and surgery for aortic dissection [2]. Data for this study were obtained from both National Health Service (NHS) Hospital Episode Statistics (HES) and the UK National Adult Cardiac Surgery Audit (NACSA). Five hundred and thirty-two patients received a thoracic aortic stent graft (TEVAR) for acute AD in the NACSA dataset. The UK National Vascular Registry (NVR) reports a further 215 patients as having had intervention, open surgical repair or 
TEVAR, by a vascular surgeon for acute AD over the years 2014-2018 (personal communication) [3]. As the number of TEVARs performed for AD is increasing, the number of AAA repairs performed is reducing [4].

Changing management of TBAD has been driven by greater access to TEVAR and its better short term outcomes as compared to open surgical repair. The ADSORB (Acute Dissection treatment with Stent graft OR Best medical therapy) trial showed benefits in the intervention group in terms of aortic remodelling at the one year follow up [5]. The INSTEAD (INvestigation of STEnt grafts in Aortic Dissection) trial provided further support for the concept of intervention in the subacute phase of TBAD (4-12 weeks) with a thoracic aortic stent graft (TEVAR) to prevent later aneurysmal degeneration, as shown in Figure 1 [6].

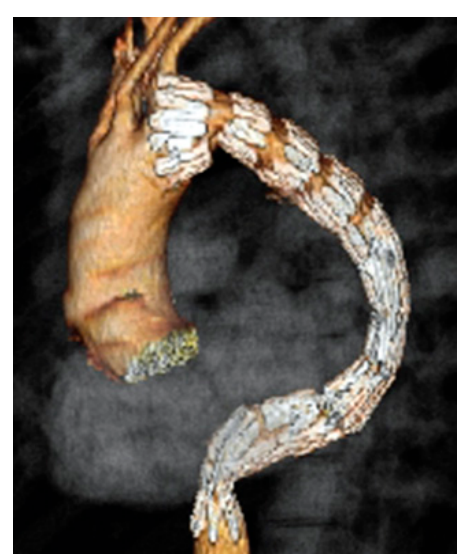

Figure 1. Acute type B aortic dissection treated with aortic stent graft (TEVAR) to exclude the proximal thoracic false lumen.

The primary aim of this study is to review published studies worldwide of acute AD incidence or treatment, focusing on acute type B aortic dissection. The review will look at the strengths and limitations of the studies identified to determine if it is possible to compare data on epidemiology and treatment across healthcare systems.

\section{Materials and Methods}

English language journals were searched using the keywords "aortic dissection" or "aorta" and "dissection" and "epidemiology" or "incidence" and "type B", as shown in Figure 2. This search was used to identify other papers reporting aortic dissection incidence from epidemiological studies, international databases (i.e., International Registry of Aortic Dissection (IRAD), Registry of Aortic Dissection in China (Sino-RAD) and Japanese dissection registry) or regional population studies (i.e., Olmstead County, Malmö Diet and Cancer Study and OxVasc). Non-English papers and non-adult papers were excluded. The 677 papers found were manually searched to identify just 31 papers in which the focus was aortic dissection epidemiology and early treatment with at least reference to type B aortic dissection. 


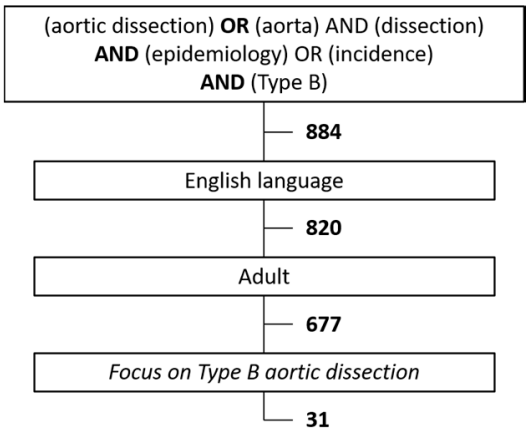

Figure 2. Search strategy.

\section{Results}

\subsection{Health Episode Statistics}

Most healthcare systems routinely collect healthcare episode statistic (HES) data using International Classification of Diseases (ICD) codes. The code for aortic dissection is I17.0. Studies usually exclude patients under 50 years of age, as these patients are more likely to have aortopathy, and some use procedural codes to distinguish between type $\mathrm{A}$ and type $\mathrm{B}$ aortic dissection.

Von Allmen et al. analysed the number of AD hospital admissions per 100,000 population from 1999-2010 in England and Wales using NHS England HES and Health Solutions Wales Patient Episode Database for Wales (PEDW) statistics [7]. Mortality data were obtained from the UK Office for National Statistics (ONS). Findings are presented for the standardised age groups 50-74 years and $\geq 75$ years in Figure 3. Over 11 years, hospitalisations for acute AD increased from 7.2 to 8.8 per 100,000 population years $(p=0.0001)$. The greatest increase was observed for patients aged $\geq 75$ years of age. The number of thoracic aortic stent graft (TEVAR) procedures increased from 0.06 to 0.53 per 100,000 population from 2006-2010 with TEVAR rates increasing 30-fold for patients aged $\geq 75$ years of age.

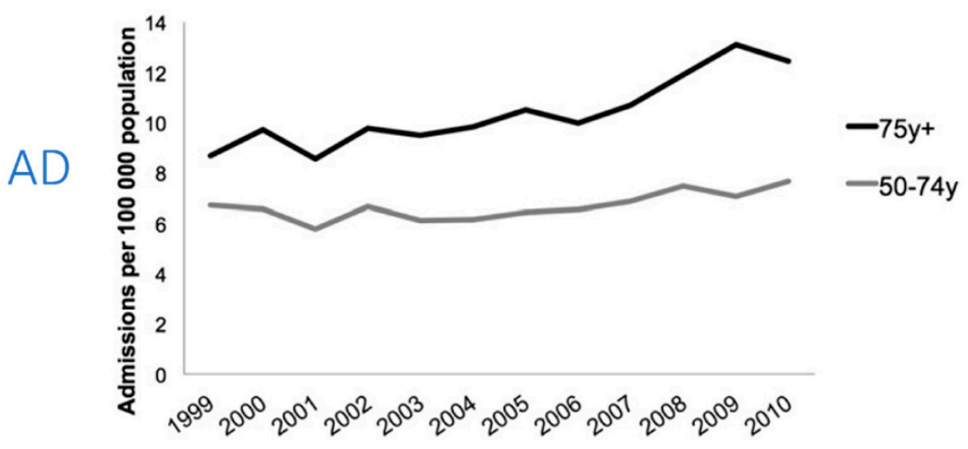

Figure 3. Admissions for thoracic aortic dissection in England and Wales 1999-2010, by age. Data were standardised by age group for International Classification of Diseases (ICD) 10 codes; I71.0.

Olsson et al., analysed Swedish national health care registers maintained by the Swedish Board of Health and Welfare, representing a population of approximately 8.7 million people, for the years 1987-2002 [8]. This analysis identified 4425 cases of acute AD; median age 70 years and $62 \%$ male. Twenty two percent of which were diagnosed post-mortem without hospitalisation. Over the 16-years the incidence of AD increased by $52 \%$ in men (10.7 to 16.3 per 100,000 person years) and $28 \%$ in women (7.1 to 9.1 per 100,000 per year). The relative risk of dissection was strongly associated with increasing age. Operations increased seven-fold in men and 15-fold in women.

Reutersberg et al. analysed 72,970 hospital admissions for acute AD in Germany between 2006-2014 [9]. Through utilising procedural codes, operated acute Type A aortic dissection, TAAD $(n=14,911)$, and TBAD $(n=5622)$ were analysed separately, as shown in Figure 4a. 
In common with other studies utilising HES data, it was not possible to differentiate between the 52,437 medically managed patients by dissection type. Operated TBAD patients were older (mean 66 years versus 64 years) and more predominantly male (71\% versus $65 \%)$. The procedural rates averaged 2.0/100,000 person years for acute TAAD and 0.7/100,000 person years for acute TBAD. The incidence of both TAAD and TBAD increased over the study period, as shown in Figure $4 \mathrm{~b}$. Open surgery declined from $12 \%$ to $3 \%$ of interventions, with 500 TEVAR procedures for acute AD now being performed each year in Germany.

(a)

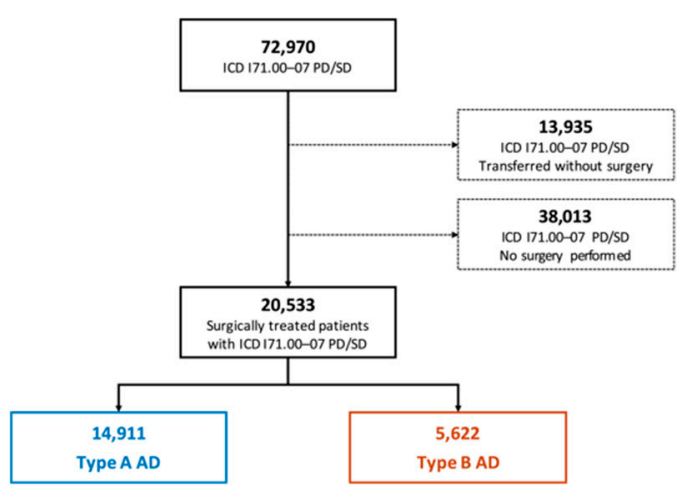

(b)

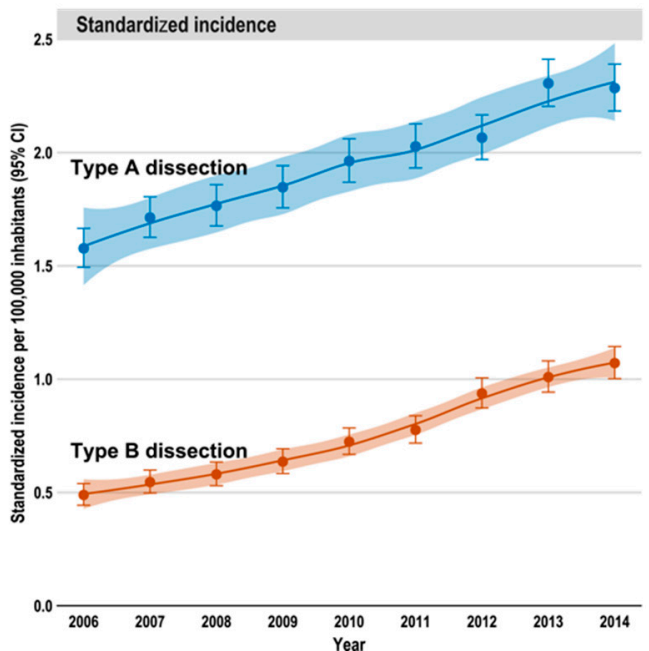

Figure 4. National healthcare statistics derived study of acute aortic dissection in Germany (2006-2014). Figure (a) shows the cases identified and (b) the standardised incidence of type A and type B aortic dissection.

Mody et al. used Medicare hospital admission data from 2000-2011 to determine trends in hospitalisation rates for acute AD in the United States of America [10]. This analysis includes 32,057 hospital admissions. The hospitalisation rate was 10/100,000 person years in people aged 65 years or older (mean age 77 years, $48 \%-53 \%$ male). TEVAR was increasingly used as a treatment across the study period, with $30 \%$ of patients having this intervention. Jones et al. used Medicare data from 2000-2010 to analyse only patients with acute TBAD who underwent TEVAR [11]. This analysis identified 11,159 patients who underwent TEVAR for acute AD. TEVAR usage increased by $21 \%$ over the 10 years from 2.5 to 3.0 per 100,000 Medicare beneficiaries per year $(p=0.001)$. The increase was most obvious from 2005 following a procedural code change.

Wang et al. investigated hospitalisation for both TBAD and thoracic aortic aneurysm using the US National Inpatient Sample (NIS) from 2000-2012 [12]. In this dataset, 155,187 patients were identified with a diagnosis of acute $\mathrm{AD}$, of whom, 46,869 were reported as having TBAD (median age 67 years, $58 \%$ male). Admission rates increased over the 12 years. Medical management was the primary therapy $(76.7 \%)$, however, TEVAR use did increase over time $(p<0.001)$. The diagnosis of hypertension was recorded for $79 \%$ of patients.

Xia et al. analysed Chinese Health Insurance Research Data (CHIRA) across the single year of 2011 [13]. This dataset comprised randomly sampled beneficiaries from the inpatient hospital records of 1.7 million male and 1.6 million female citizens from 25 cities and counties in mainland China. Sixty-five patients were identified with acute AD within the 300,886 records. Mean age was $58.9 \pm 13.4$ years and $72 \%$ were male. The rate of hospitalisation for acute AD was 2.0 per 100,000 person years. The authors used this data to estimate a population incidence for mainland China of 2.8 per 100,000 person years (95\% confidence interval (CI): 1.9-3.6). The hospitalisation rate varied with age and gender, as shown in Figure 5. Treatment was medical in $63 \%$, TEVAR in $20 \%$ and open surgery in $17 \%$ of patients. 


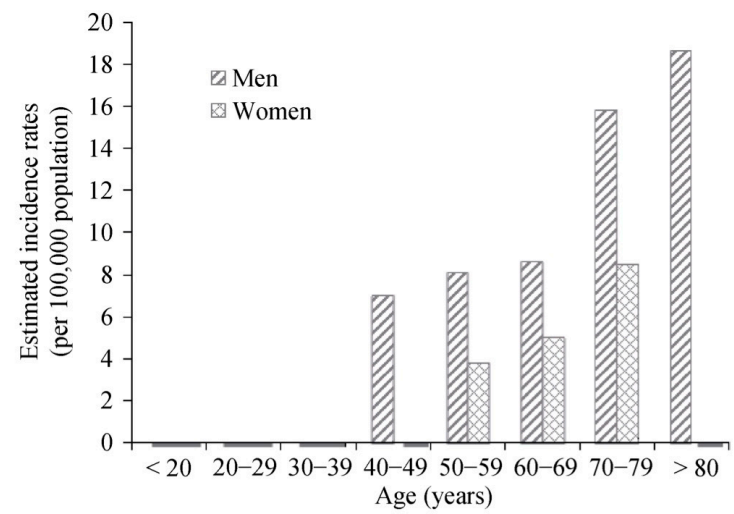

Figure 5. Estimated incidence rate for acute aortic dissection (type A and B) in mainland China according to age and sex.

Yu et al. analysed 5654 cases from the Taiwan National Health Insurance (NHI) Research Database from 1996 to 2001 (NHI has >99\% coverage in Taiwan, with 23 million people being enrolled in 2014) [14]. Acute AD was diagnosed in 5654 people (median age 64 years, 68.5\% male). The incidence of acute AD hospitalisation was 4.3 per 100,000 person years. Twenty percent of patients underwent surgery. Yeh et al., repeated this analysis for the years 2005 to 2012 [15]. Over the 7 years, AD was diagnosed in 9092 people, with operated TAAD in 2340 people (25.7\%) and operated TBAD in 1144 people $(12.6 \%)$. The incidence of acute AD hospitalisation was 5.6 per 100,000 people years ( 8.0 per 100,000 for men and 3.2 per 100,000 for women). Hypertension was the most commonly identified AD risk factor ( $54 \%)$, followed by coronary artery disease $(20 \%)$ and chronic obstructive pulmonary disease $(14 \%)$. Annual incidence trends revealed an increase with time $(p<0.0001)$.

Dias et al. used data from the public health service in São Paulo, Brazil, for hospitalisations, procedures and deaths to identify people with thoracic aortic aneurysm or dissection. In total, 10,019 people were diagnosed with acute AD diagnosed from 1998 to 2007 [16]. In 6721 people (67\%) the diagnosis was made following an out of hospital death. The rates of both TBAD deaths and hospitalisations increased over the period of the study.

Jiménez-Trujillo et al. analysed the Conjunto Minimo Básico de Datos (CMBD) Spanish National Hospital Database, which covers $>90 \%$ of hospital discharges in Spain, to identify people hospitalised with acute AD from 2001-2012 [17]. This study identified 48,746 patients over 50 years of age. Both hospitalisation and treatment with TEVAR increased over the study period. Treatment with open surgery reduced. The incidence of acute AD was not analysed as the focus of this paper was on differences in outcomes for patients with or without diabetes (patients with diabetes had a low hospitalisation rate in three of the four time periods studied).

Smedberg et al., this year, published data from the Swedish National Patient Register and Cause of Death Register for the period 2002-2016 [18]. In this study, 8057 patients (median age 68 years, $64 \%$ male) were diagnosed with acute AD. The diagnosis was made post-mortem without hospital admission in $29 \%$ of patients. The incidence of acute AD was calculated as 7.2 per 100,000 person years (9.1 in men and 5.4 in women). The incidence of AD was observed to decrease over time. Four percent of patients with TBAD were treated with TEVAR and $<1 \%$ underwent open surgical repair.

Avdic et al. used the Swedish National Diabetes Register with links to other Swedish national datasets of people without diabetes to obtain data on 448,319 people with type II diabetes mellitus between 1999 and 2015 [19]. In a subgroup analysis, people with diabetes were less likely to suffer an acute AD than controls (HR 0.53, 95\% CI 0.42-65, $p<0.0001$ ).

\subsection{Prospective Epidemiological Studies}

The Olmsted County study, Clouse et al., from the Mayo clinic, studied a rural US community in Minnesota from 1980 to 1994 [20]. Over the 14 years, the AD incidence was 2.6, increasing to 
3.5 per 100,000 person years. Just six people were diagnosed with acute TBAD (median age 67 years, $64 \%$ male), giving an incidence of TBAD of 0.5 per 100,000 person years. For comparison, 39 patients suffered acute TAAD. In 2018, DeMartino et al. published a follow up study for the same population over the period 1995-2015 [21]. In these 10 years, 75 people with acute AD were identified (median age 72 years, 57\% male). The incidence of acute AD was 4.4 per 100,000 person years. Between 1995 and 2015 , the incidence of AD was stable. The incidence was higher in people aged $>70$ years.

Melvinsdottir et al. published the incidence of acute AD in the Icelandic population from 1992 to 2013 (300,000 people) [22]. Data for this study were collected from hospital records, post-mortem examinations and death certificates. One hundred and one people were diagnosed with acute TAAD and 52 people with acute TBAD. Of these, $21.4 \%$ of people died outside of a hospital. The age- and gender-adjusted incidence for TAAD and TBAD was 2.5 and 1.0 per 100,000 person years, respectively (median age 67 years, $61 \%$ male). Aortic dissection incidence was observed to be stable across the study period. Hypertension was recorded for $57.5 \%$ of people. Smoking rates were $10 \%$ higher in patients with acute TBAD. In hospitalised patients, $26 \%$ (13/50) underwent surgery. Surgery changed from open surgical repair to TEVAR over the study period.

The OxVasc study examined cardiovascular disease prevalence in people registered with nine rural general practices in Oxfordshire, England [1]. Thirty-seven acute type A AD and 15 acute type B AD were reported by Howard et al. in this population of 92,728 people over a 10-year period. The incidence of acute AD was calculated as 6 per 100,000 person years. The impact of both age and gender on AD incidence are shown in Figure 6. The authors used Poisson regression analysis to calculate the relative risk (RR) of acute $\mathrm{AD}$ for men in 10 year age bands: assigning a RR of 1 for men aged less than 30. The RR increased to 9.0 for $40-49$ yeas (95\% CI 7.5-10.8), 26.4 for years $50-59$ (95\% CI 22.3-21.3) and 137 for men aged over 70 years (95\% CI 116.4-160.8). Women, on average, presented with acute $\mathrm{AD}$ aged 10 years older than men.

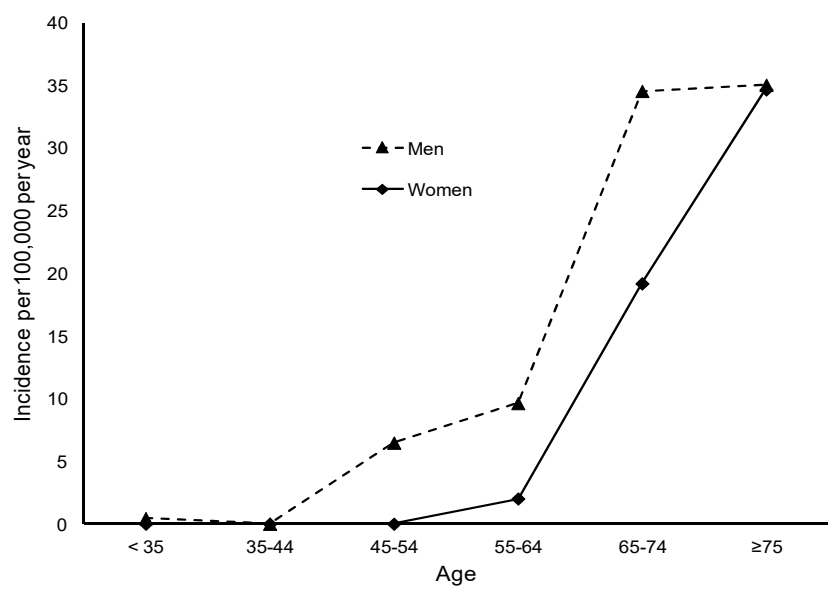

Figure 6. Incidence of aortic dissection from the OxVasc Study (University of Oxford) by age and gender for 2002-2012.

Landenhed et al. used data from the 30,412 middle-aged individuals without a diagnosis of aortic disease at baseline enrolled prospectively into the Malmö Diet and Cancer study (Sweden) [23]. During a median of 16 years follow up, the incidence of acute AD was observed as 15 per 100000 person years (95\% CI 11.7 to 18.9$)$. The study population had an average age of 70 years and $66 \%$ were male. The observed incidence of acute $\mathrm{AD}$ was $55 \%$ that of rupture abdominal aortic aneurysm, and $156 \%$ that of ruptured thoracic aortic aneurysm. A diagnosis of hypertension was associated with a significantly increased risk of acute $\mathrm{AD}$ (HR 2.64, 95\% CI 1.33 to 5.25). 


\subsection{Disease Specific Registries}

The International Registry of Acute Aortic Dissection (IRAD) was established in 1996 across 12 centres in 6 countries. Hagan et al., reported IRAD data showing that patients presenting TBAD were older than patients with TAAD, and had higher rates of atherosclerosis [24]. In 2015, Pape el al. reported 17 year trends for acute AD within IRAD [25]. This analysis included 1476 patients from 28 centres across North America, Europe and Asia. The proportion of hospitalisations for TBAD was one third that of all acute AD admissions. The prevalence of hypertension in patients with AD was $81 \%$. Four percent of patients had a diagnosis of Marfan syndrome (MFS). Treatment using TEVAR increased from $7 \%$ to $31 \%(p<0.001)$, and open surgical repair reduced, as shown in Figure 7.

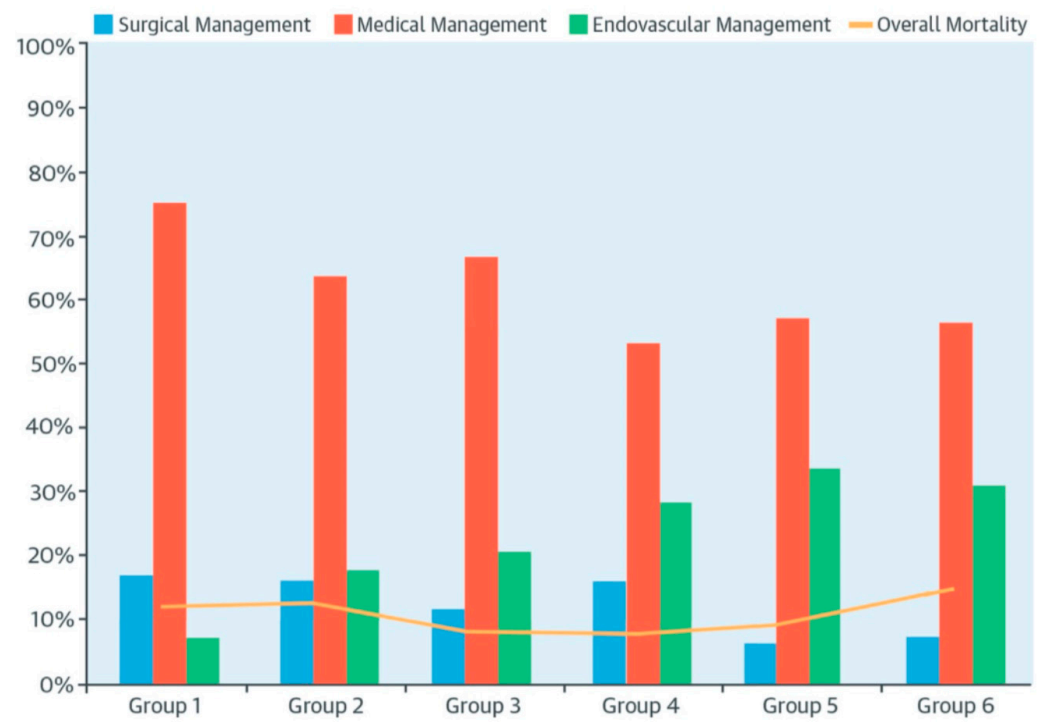

Figure 7. Trends in aortic dissection over 17 years in the International Registry of Aortic Dissection (IRAD).

Wang et al. analysed 1003 patients enrolled into the Registry of Aortic Dissection in mainland China (Sino-RAD) by 14 centres from 2011-2014 [26]. Patients enrolled in Sino-RADwere compared with patients in IRAD. The proportion of patients in Sino-RAD with MFS, hypertension and arteriosclerosis was less for all conditions than that in IRAD $(p<0.01)$. A significantly high proportion, $76 \%$ versus $31 \%$, of patients with TBAD in Sino-RAD underwent TEVAR.

Yamaguchi et al. reported that 8217 type B AD patients had been enrolled in a Japanese AD registry by 2019 [27]. No published reports from this registry could be found.

\subsection{Clinical Studies (Hospitalisation)}

\subsubsection{Sweden}

Acosta and Gottsäter, studied the periods 2000-2004 and 2014-2016 in Malmö [28]. Their estimate for acute AD incidence was 2.4 per 100,000 person years (5.5 for 2000-2004 and 3.3 for 2014-2016). The incidence of acute TBAD was 2.1 per 100,000 person years for 2000-2004 and 0.5 per 100,000 person years for 2014-2016. History of smoking and/or of hypertension were identified as risk factors. For 2000-2004, the time period over which the Malmö Diet and Cancer study was conducted, the incidence of acute $\mathrm{AD}$ in the age category 65-84 years was 26 per 100,000 person years. This is significantly higher than the 15 per 100,000 person years reported by Landenhed et al. [23]. The difference was attributed to better case ascertainment in this focused AD study. Acosta and Gottsäter noted that the rate of post-mortems had reduced from $25.2 \%$ to $16.1 \%$ between the two time periods studied $(p<00001)$. They associated the fall in post-mortems with a significant reduction in the proportion of TAAD diagnosed as an out of hospital death from $78 \%$ to $48 \%$. In contrast, the proportion 
of TBAD diagnosed out of hospital rose remained the same (21\% to $22 \%$ ). The average age of patients in the second time period was also younger (mean age 61 years versus 73 years, $55 \%$ male versus $56 \%$ male). Eighty two percent of patients with TBAD were treated medically.

\subsubsection{Italy}

Pacini et al. analysed a database of hospital admissions in the Emilia-Romagna region [29]. From 2000 to 2008, 1499 hospitalisations with a diagnosis of acute AD were identified (mean age 68 years, $64 \%$ male). The hospitalisation rate for acute AD was 4.7 per 100,000 person years. The authors noted that a high proportion of the patients were aged $\geq 80$ years. Hospitalisations for acute AD increased over the 8 years.

\subsubsection{Germany}

Ante et al. report that 229 patients were admitted to Heidelberg and Cologne with the diagnosis of an acute TBAD over a 13 year period [30]. They considered 78 dissections to be "complicated" and 151 "uncomplicated" based on the presence or absence of aortic rupture, early expansion, aortic side branch mal perfusion (visceral, renal, spinal or lower limb ischaemia), uncontrolled hypertension or ongoing aortic pain. Sixty-two "uncomplicated" patients underwent early TEVAR (41\%).

\subsubsection{Hungary}

Mészáros et al. report acute AD hospitalisations or deaths over 27 years in the population of Sumeg, Veszprém county [31]. Sixty-six hospitalised and 18 non-hospitalised patients (post-mortem diagnoses) were identified (post-mortem diagnosis in 21\%). The incidence of acute AD was 2.9 per 100,000 person years (median age 84 years, $64 \%$ male).

\subsubsection{Canada}

McClure et al. studied admissions with acute AD to Ontario hospitals from 2002-2014 [32]. There were 5966 patients with AD diagnosed, of which 3632 were type B AD (median age 66 years, $61 \%$ male, ratio TAAD:TBAD 1:1.56). The hospitalisation rate for acute AD was 4.6 per 100,000 person years and acute TBAD 2.8 per 100,000 person years. The number of admissions for acute TBAD increased significantly over time. Treatment for TBAD was primarily medical $(83 \%)$. Overall, $10 \%$ of people had open surgical repair and $7 \%$ received TEVAR.

\subsubsection{Mainland China}

Li et al. retrospectively analysed data from 1812 patients in 19 hospitals from 2008 to 2011 [33]. This data included 1086 people with acute TBAD. The mean age was 51 years (10-20 years younger than in most other AD series) and 77\% were male. TEVAR was performed in $76.1 \%$. A similarly high percentage of acute TBAD patients treated using TEVAR is also reported in a meta-analysis of Chinese acute AD publications by Xiong et al. [34]. This meta-analysis identified 175 studies reporting TEVAR for AD from Shanghai, Beijing, Hubei and Guangdong between 2008-2015. Seventy percent of these procedures were in the acute setting. In 2011, Wang et al. published a review of AD treatment in mainland China (2000-2009) [35]. Eleven articles with 1226 cases from eight medical centres (Beijing, Shanghai, Guangzhou, Wuhan, Dalian, Yinchuan, Urumqi and Nanjing) were included and compared to 1115 IRAD cases. Chinese patients were younger $(52.6 \pm 2.8$ versus $62.4 \pm 13.9$ years, $p<0.001)$ and the proportion of males was higher $(80.7 \%$ versus $68.8 \%, p<0.001)$. In both data sets, patients with TBAD had an older mean age than patients with TAAD (mainland China by 5 years; IRAD by 3 years). Hypertension was equally prevalent in both data sets $(69.7 \%$ versus $72.0 \%$, ns). Li et al. have published a more recent systematic review from January 1999 to October 2014 [36]. In this meta-analysis 75 papers were retrieved (four English, 66 Chinese) with a total of 3396 patients. The mean age ranged from 43 to 65 years and $80.7 \%$ were male. 
Xia et al. have this year published a study from Tonhji Hospital (Wuhan, Hubei province) [37]. Data were collected using electronic patient records from 2048 patients presenting with acute AD from 2011-2018 (mean age 53.4 years, $81 \%$ male). The ratio of acute TAAD to acute TBAD was $45.7 \%$ to $54.3 \%$. No data on incidence were presented as the paper's focus was on the timing of presentation, with more cases presenting in winter months.

\subsubsection{Japan}

Takeuchi et al. reported 240 consecutive patients admitted to hospital with a diagnosis of acute AD in Kurume, Japan [38]. The authors did not estimate the incidence for acute AD. They did, however, identify low albumin (OR 0.004 per gm/dL) and smoking (OR 3.475) as risk factors.

\section{Discussion}

This study reviews the published English language literature on the incidence of acute AD, with a focus on the epidemiology and treatment of acute TBAD. Hospital episode statistics (HES) data were available from six countries (UK, Sweden, Germany, USA, mainland China and Taiwan). Four population based epidemiological studies (USA, Iceland, UK and Sweden) and two large registries (IRAD and Sino-RAD) have published data [24-26]. There are a number of smaller observational studies of varying population size and quality. Several of the studies report TBAD treatment with no data on incidence. Many studies reported a composite figure for both TAAD and TBAD. Table 1 provides a summary of the study findings from the selected papers.

Table 1. Studies reporting incidence of aortic dissection.

\begin{tabular}{|c|c|c|c|c|c|c|c|c|}
\hline \multirow{2}{*}{$\begin{array}{l}\text { (http://creativecommons.org/ } \\
\text { licenses/by/4.0/).Authors }\end{array}$} & \multirow{2}{*}{$\begin{array}{l}\text { Years } \\
\text { Studied }\end{array}$} & \multirow{2}{*}{$\begin{array}{l}\text { Study } \\
\text { Size }(n)\end{array}$} & \multirow[t]{2}{*}{ Age } & \multirow[t]{2}{*}{ Male (\%) } & \multicolumn{2}{|c|}{$\begin{array}{c}\text { Incidence Per } \\
100,000 \text { Person Years }\end{array}$} & \multirow{2}{*}{$\begin{array}{l}\text { Operated } \\
\text { TBAD }(\%)\end{array}$} & \multirow{2}{*}{$\begin{array}{l}\text { Trend Over } \\
\text { Time }\end{array}$} \\
\hline & & & & & AD & TBAD & & \\
\hline \multicolumn{9}{|c|}{ Population based studies $^{1}$} \\
\hline Landenhead, et al. [23] & 1991-2011 & 70 & 62 & $66 \%$ & 15 & 6.3 & - & - \\
\hline Mészáros, et al. [31] & $1973-2000$ & 84 & 66 & $64 \%$ & 2.9 & - & - & - \\
\hline Olsson, et al. [8] & 1987-2002 & 4425 & 70 & $62 \%$ & - & - & - & $\uparrow$ \\
\hline Dias, et al. [16] & 1998-2007 & 10,019 & - & $58 \%$ & - & - & - & $\uparrow$ \\
\hline Howard, et al. [1] & 2002-2012 & 59 & 72 & $60 \%$ & 6.0 & 1.7 & $26 \%$ & - \\
\hline Melvinsdottir, et al. [22] & 1992-2013 & 153 & 67 & $61 \%$ & 2.5 & 1.0 & $26 \%$ & $\rightarrow$ \\
\hline \multirow{2}{*}{$\begin{array}{l}\text { Clouse, et al. [20] } \\
\text { DeMartino, et al. [21] }\end{array}$} & 1980-1994 & 39 & 67 & $64 \%$ & $2.6-3.5$ & 0.5 & - & $\uparrow$ \\
\hline & 1995-2015 & 77 & 72 & $57 \%$ & 4.4 & - & - & $\rightarrow$ \\
\hline \multirow{2}{*}{ Acosta \& Gottsäter [28] } & $2000-2004$ & 73 & 73 & $55 \%$ & 5.5 & 2.1 & - & - \\
\hline & $2014-2016$ & 32 & 61 & $56 \%$ & 3.3 & 0.9 & $18 \%$ & $\downarrow$ \\
\hline Smedberg, et al. [18] & $2002-2016$ & 8057 & 68 & $64 \%$ & 7.2 & - & - & $\downarrow$ \\
\hline \multicolumn{9}{|c|}{ Hospital based studies } \\
\hline Yu, et al. [14] & 1996-2001 & 5654 & 64 & $69 \%$ & 4.3 & - & - & - \\
\hline Pacini, et al. [29] & $2000-2008$ & 1449 & 68 & $64 \%$ & 4.7 & - & - & $\uparrow$ \\
\hline von Allmen, et al. [7] & 1999-2010 & - & - & - & $7.2-8.8$ & - & $53 \%$ & $\uparrow$ \\
\hline Mody, et al. [10] & $2000-2011$ & 32,057 & 77 & $48-53 \%$ & 10 & - & $30 \%$ & $\rightarrow$ \\
\hline Li, et al. [33] & $2008-2011$ & 1812 & 51 & $77 \%$ & - & - & $76 \%$ & - \\
\hline Xia, et al. [13] & 2011 & 65 & 59 & $72 \%$ & $2.0^{1}$ & - & $35 \%$ & - \\
\hline Wang, et al. [12] & $2000-2012$ & 46,869 & 67 & $58 \%$ & - & - & $23 \%$ & $\uparrow$ \\
\hline Yeh, et al. [15] & $2005-2012$ & 9092 & 64 & $72 \%$ & 5.6 & - & $13 \%$ & $\uparrow$ \\
\hline McClure, et al. [32] & 2002-2014 & 5966 & 66 & $61 \%$ & 4.6 & 2.8 & $17 \%$ & $\uparrow$ \\
\hline Reutersberg, et al. [9] & & - & - & - & 2.8 & - & $27 \%$ & \\
\hline Operated Type A: & 2006-2014 & 72,970 & 64 & $65 \%$ & - & - & - & $\uparrow$ \\
\hline Operated Type B: & & $148,115,622$ & 66 & $71 \%$ & - & - & - & \\
\hline Xia et al. [37] & 2011-2018 & 2048 & 53 & $81 \%$ & - & - & - & - \\
\hline
\end{tabular}

AD: Aortic dissection. TBAD: Type B aortic dissection. Data specific to TBAD has been highlighted. ${ }^{1}$ A population incidence for acute AD in mainland China of 2.8 per 100,000 population years.

The range of reported acute AD incidence was 2 to 15 per 100,000 person years. The reported incidence for acute TBAD was 0.5 to 6.3 per 100,000 person years [1,9,20,22,23,28,32]. In IRAD, the incidence of TBAD is consistently one third that of TAAD [24]. A ratio of 2.6:1 between TAAD and TBAD was observed in studies by Clouse et al. (Olstead County, USA) and Acosta and Gottsäter (Malmö, Sweden) [20,28]. 
A significant study limitation is that the type of aortic dissection, ascending or descending, is not captured in ICD codes. This means that for medically managed patients, it not possible to separate TAAD from TBAD. In operated patients the inability of procedural codes to differentiate the urgency of treatment ("emergent", "urgent" or "elective") may also lead to incorrect allocation of treatment type.

Population based prospective epidemiological studies should provide the best data on AD incidence. However, the absolute numbers of TBAD cases identified are small in the four reported studies; OxVasc $(n=15)$, Olmstead County $(n=6)$, Icelandic population $(n=52)$ and Malmö Diet and Cancer study $(n=30)[1,20,22,23]$. The variation in acute AD incidence between populations is highly influenced by age, as shown by Howard et al. in the OxVasc data, as shown in Figure 6 [1]. Consistently across studies, older age is associated with a higher AD incidence. In the study by Landenhead et al., the reported acute $\mathrm{AD}$ incidence in the Malmö population - with a median age of 70 years-is 15 per 100,000 person years (6.3 per 100,000 person years for acute TBAD) [23]. Acosta and Gottsäter report a higher incidence of 26 per 100,000 person years in this same Malmö population [28]. Mody et al. used US Medicare data to give an acute AD hospitalisation rate of 10 per 100,000 person years in a cohort of over 30,000 people with median age of 77 years [10]. Howard et al. and Olsson et al. have published the relative risk for $\mathrm{AD}$ by age group $[1,8]$.

A gender difference, a higher TAAD prevalence in males, was observed in a large German dataset for the open repair of acute TAAD (GERAADA) [39]. In the studies identified here, the proportion of females with acute AD varied from $19 \%$ to $52 \%$. The lowest female proportions are reported in mainland China (19-28\%) [13,33,35,37]. Women were observed to present with acute AD at an older age than men; the mean age difference was 10 years in the OxVasc study (United Kingdom) and 5 years in the study by Smedberg et al. (Sweden) [1,18]. There was also a higher proportion of out of hospital deaths observed in women in both these studies.

Out of hospital deaths are a potential cause of the under-reporting of acute AD incidence. In the study by Dias et al. (São Paulo, Brazil), 68\% of AD cases were identified as out of hospital deaths [16]. The proportion of out of hospital deaths reported in other studies is lower; Olsson et al.—22\%, Melvinsdottir et al.—21\%, Acosta and Gottsäter TAAD-78\%/43\% and TBAD—21\%/22\%, Smedberg et al.—29\% and Mészáros et al.—21\% [8,18,22,28,31]. The proportion of TBAD deaths is less than TAAD deaths, but remains significant, especially if the calculated AD incidence figure is extrapolated to be applied to a larger population. Ascertainment of pre-hospital deaths is becoming more difficult, as in many countries post-mortem examinations are now rarely performed. Takeuchi et al. have suggested the use of CT to make the diagnosis of acute AD following an out of hospital sudden death [40].

Disease specific registry data and the observational studies are inevitably subject to selection bias, typically with more complete entry and more aggressive surgical treatment in large specialist units. This may explain the high treatment rates with TEVAR in the studies by Li and Xiong from mainland China $[33,34]$. Bottle et al. have reported wide variation in UK aortic management, between $7.6 \%$ and $31.5 \%$ intervention rates, across different regions [2]. This variation may be explained in part by the absence of formal aortic dissection pathways, resulting in patients with TBAD being managed in different ways by a cardiologists, vascular surgeons and cardiac surgeons.

INSTEAD provided limited level one (randomized trial) evidence that thoracic aortic stenting in the subacute phase (4-12 weeks) is safe and reduces the risk of late aneurysmal degeneration [5]. TEVAR in this trial was associated with increased early risk of retrograde aortic dissection, stroke $(n=1)$ and spinal cord ischaemia $(n=2)$. In a meta-analysis by Chen et al., the relative risk of retrograde dissection following TEVAR is 5.33 times higher than when treating a degenerative aneurysm $(95 \%$ CI 2.70-10.51) [41]. In a meta-analysis by Hossack et al., the risk of stroke was increased by $50 \%$ (OR 1.56, 95\% CI 1.17-2.08, $p=0.002$ ) [42]. The ADSORB study showed the benefit of TEVAR in reducing the rate of aortic dilatation after acute AD. [4] Hossack et al.'s meta-analysis supports intervention with TEVAR for acute AD as both late all-cause mortality (HR 1.54, 95\% CI 1.27-1.86, $p<0.001$ ) and aorta related mortality (HR 2.71, 95\% CI 1.49-4.94, $p=0.001$ ) improved with TEVAR, in addition to the 
best medical therapy [42]. Follow up has been short in most studies and overall the evidence base for TEVAR in acute AD is weak. It is therefore striking that the rate of TEVAR is increasing fast, with $76 \%$ of patients receiving TEVAR in one study [33]. The more consistent range of TEVAR usage in acute AD is $15 \%-30 \%[1,9,10,12,14,15,22,28,32]$.

Whilst aortopathy is an important cause of acute AD in younger patients, the absolute number of people affected is small. Many of the studies presented excluded people aged $<50$ years. AD incidence is linked to rates of smoking, hypertension and other atherosclerotic risk factors. In mainland China, prevalence of hypertension is high, rates of hypertension treatment are low, and 2015 WHO data report smoking rates of $47.6 \%$, as compared to $19 \%$ in the USA $[43,44]$. Smoking demographics and access to healthcare, for instance for the monitoring and control of hypertension, may be important influencers of AD incidence between countries and over time. A meta-analysis to investigate these risk factors would require new studies with standardised end points.

Coding errors and omissions are well reported in routinely collected hospital data [45]. There is also the risk of over counting; patients with AD are frequently readmitted, for instance for "subacute" endovascular intervention, and can easily be counted twice in hospital episode datasets. Some studies look back 2 years for previous coding of an AD diagnosis. For a chronic disease this time period may not be sufficient to discriminate acute and chronic dissection. The limitations of HES data have been widely discussed elsewhere and this discussion will not be repeated here $[46,47]$. Specifically for AD, a study by Banerjee et al. investigating acute AD in pregnancy in the UK, recently demonstrated the difficulties of making comparisons between data sets [48]. In this study the annual incidence of acute AD between 2003-2011 was reported as 1.23 per 100,000 maternities in NHS hospital episode statistics (HES), but as 0.80 per 100,000 maternities in the UK Obstetric Surveillance System (UKOSS), a national system to record rare disorders in pregnancy.

Other than when the method of data collection changes, hospital episode statistics can provide an accurate indication of trends over time. Whilst Mody et al. showed no increase in US Medicare admissions for acute AD for the years 2000-2011 [10], consistently across other studies, hospitalisation for acute $\mathrm{AD}$ has been shown to be increasing worldwide. The actual incidence of AD is less certain, as recognised in the 2015 European Society of Cardiology (ESC) guidelines [49]. Acute AD incidence was reported to be increasing between 1987 to 2013 in three studies [8,16,22]. However, more recent studies suggest incidences to be stabilising, or even falling $[18,23,28]$. A falling incidence would be consistent with data showing that in many countries cardiovascular risk factors are being better addressed.

In conclusion, there remains uncertainty regarding the incidence of acute TBAD. Changing incidence could be attributed to changes in population demographics and changing exposure to cardio-vascular risk factors. It equally may reflect changes in diagnosis and coding of cases (case ascertainment). The treatment for acute TBAD remains predominantly medical, with control of hypertension and serial cross-sectional imaging. There is increasing use of thoracic aortic stent grafts worldwide, despite a limited evidence base for this change of practice. For future studies, specific ICD-10 codes of acute, chronic, ascending and descending aortic dissection would greatly improve the ability to compare data on acute TBAD incidence and treatment between countries. Similarly, TEVAR codes should include whether the procedure is urgent or elective, as is the case for open aortic replacement.

Funding: This research received no external funding.

Conflicts of Interest: The author declares no conflict of interest. 


\section{References}

1. Howard, D.P.J.; Banerjee, A.; Fairhead, J.F.; Perkins, J.; Silver, L.E.; Rothwell, P.M. Population-based study of incidence and outcome of acute aortic dissection and premorbid risk factor control clinical perspective: 10-year results from the Oxford vascular study. Circulation 2013, 127, 2031-2037. [CrossRef] [PubMed]

2. Bottle, A.; Mariscalco, G.; Shaw, M.A.; Benedetto, U.; Saratzis, A.; Mariani, S.; Bashir, M.; Aylin, P.; Jenkins, D.; Oo, A.Y.; et al. Unwarranted Variation in the Quality of Care for Patients with Diseases of the Thoracic Aorta. J. Am. Heart Assoc. 2017, 6, e004913. [CrossRef] [PubMed]

3. Waton, S.; Royal College of Surgeons of England, London, UK. Personal communication, 2019.

4. National Vascular Regsitry 2019 Annual Report. Available online: https://www.vsqip.org.uk/content/uploads/ 2019/12/NVR-2019-Annual-Report.pdf (accessed on 15 October 2020).

5. Brunkwall, J.; Kasprzak, P.; Verhoeven, E.; Heijmen, R.; Taylor, P.; Alric, P.; Canaud, L.; Janotta, M.; Raithel, D.; Malina, M.; et al. Endovascular repair of acute uncomplicated aortic type B dissection promotes aortic remodelling: 1 year results of the ADSORB trial. Eur. J. Vasc. Endovasc. Surg. 2014, 48, 285-291. [CrossRef] [PubMed]

6. Nienaber, C.A.; Kische, S.; Rousseau, H.; Eggebrecht, H.; Rehders, T.C.; Kundt, G.; Glass, A.; Scheinert, D.; Czerny, M.; Kleinfeldt, T.; et al. Endovascular repair of type B aortic dissection: Long-term results of the randomized investigation of stent grafts in aortic dissection trial. Circ. Cardiovasc. Interv. 2013, 6, 407-416. [CrossRef] [PubMed]

7. von Allmen, R.S.; Anjum, A.; Powell, J.T. Incidence of descending aortic pathology and evaluation of the impact of thoracic endovascular aortic repair: A population-based study in England and Wales from 1999 to 2010. Eur. J. Vasc. Endovasc. Surg. 2013, 45, 154-159. [CrossRef]

8. Olsson, C.; Thelin, S.; Ståhle, E.; Ekbom, A.; Granath, F. Thoracic aortic aneurysm and dissection: Increasing prevalence and improved outcomes reported in a nationwide population-based study of more than 14,000 cases from 1987 to 2002. Circulation 2006, 114, 2611-2618. [CrossRef]

9. Reutersberg, B.; Salvermoser, M.; Trenner, M.; Geisbüsch, S.; Zimmermann, A.; Eckstein, H.-H.; Kuehnl, A. Hospital Incidence and In-Hospital Mortality of Surgically and Interventionally Treated Aortic Dissections: Secondary Data Analysis of the Nationwide German Diagnosis-Related Group Statistics From 2006 to 2014. J. Am. Heart Assoc. 2019, 8, e011402. [CrossRef]

10. Mody, P.S.; Wang, Y.; Geirsson, A.; Kim, N.; Desai, M.M.; Gupta, A.; Dodson, J.A.; Krumholz, H.M. Trends in aortic dissection hospitalizations, interventions, and outcomes among Medicare beneficiaries in the United States, 2000-2011. Circ. Cardiovasc. Qual. Outcomes 2014, 7, 920-992. [CrossRef]

11. Jones, D.W.; Goodney, P.P.; Nolan, B.W.; Brooke, B.S.; Fillinger, M.F.; Powell, R.J.; Stone, D.H. National trends in the utilization, mortality, and survival after repair of type $\mathrm{B}$ aortic dissection in the Medicare population. JVS 2014, 60, 11-19. [CrossRef]

12. Wang, G.J.; Jackson, B.M.; Foley, P.J.; Damrauer, S.M.; Goodney, P.P.; Kelz, R.R.; Wirtalla, C.; Fairman, R.M. National trends in admissions, repair, and mortality for thoracic aortic aneurysm and type B dissection in the National Inpatient Sample. J. Vasc. Surg. 2018, 67, 1649-1658. [CrossRef]

13. Xia, L.; Li, J.H.; Zhao, K.; Wu, H.Y. Incidence and in-hospital mortality of acute aortic dissection in China: Analysis of China Health Insurance Research (CHIRA) Data 2011. J. Geriatr. Cardiol. 2015, 12, 502-506. [PubMed]

14. Yu, H.Y.; Chen, Y.S.; Huang, S.C.; Chiu, C.C.; Lai, W.T.; Huang, B. Late outcome of patients with aortic dissection: Study of a national database. Eur. J. Cardiothorac. Surg. 2004, 25, 683-690. [CrossRef] [PubMed]

15. Yeh, T.Y.; Chen, C.Y.; Huang, J.W.; Chiu, C.C.; Lai, W.T.; Huang, Y.B. Epidemiology and Medication Utilization Pattern of Aortic Dissection in Taiwan. A Population-Based Study. Medicine 2015, 94, e1522. [CrossRef] [PubMed]

16. Dias, R.R.; Mejia, O.A.V.; Fernandes, F.; Ramires, F.J.A.; Mady, C.; Stolf, N.A.G.; Jatene, F.B. Mortality impact of thoracic aortic disease in São Paulo state from 1998 to 2007. Arquivos Brasileiros Cardiol. 2013, 101, 528-535. [CrossRef] [PubMed]

17. Jiménez-Trujillo, I.; González-Pascual, M.; Jiménez-García, R.; Hernández-Barrera, V.; Miguel-Yanes, J.M.; Méndez-Bailón, M.; de Miguel-Diez, J.; Salino-Fort, M.A.; Perez-Farinos, N.; Carrosco-Garrido, P.; et al. Type 2 Diabetes Mellitus and Thoracic Aortic Aneurysm and Dissection. An Observational Population-Based Study in Spain from 2001 to 2012. Medicine 2016, 95, e3618. 
18. Smedberg, C.; Steuer, J.; Leander, K.; Hultgren, R. Sex differences and temporal trends in aortic dissection: A population-based study of incidence, treatment strategies, and outcome in Swedish patients during 15 years. Eur. Heart J. 2020, 41, 2430-2438. [CrossRef]

19. Avdic, T.; Franzén, S.; Zarrouk, M.; Acosta, S.; Nilsson, P.; Gottsäter, A.; Svensson, A.-M.; Gudbjörnsdottir, S.; Eliassön, B. Reduced Long-Term Risk of Aortic Aneurysm and Aortic Dissection Among Individuals with Type 2 Diabetes Mellitus: A Nationwide Observational Study. J. Am. Heart Assoc. 2018, 7, e007618. [CrossRef]

20. Clouse, W.D.; Hallett, J.W.; Schaff, H.V.; Spittell, P.C.; Rowland, C.M.; Ilstrup, D.M.; Melton, L.J. Acute aortic dissection: Population-based incidence compared with degenerative aortic aneurysm rupture. Mayo Clin. Proc. 2004, 79, 176-180. [CrossRef]

21. DeMartino, R.R.; Sen, I.; Huang, Y.; Bower, T.C.; Oderich, G.S.; Pochettino, A.; Greason, K.; Kalra, M.; Johnstone, J.; Shuja, F.; et al. A Population-Based Assessment of the Incidence of Aortic Dissection, Intramural Hematoma and Penetrating Ulcer, and Its Associated Mortality from 1995 to 2015. Circ. Cardiovasc. Qual. Outcomes 2018, 11, e004689. [CrossRef]

22. Melvinsdottir, I.H.; Lund, S.H.; Agnarsson, B.A.; Sigvaldason, K.; Gudbjartsson, T.; Geirsson, A. The incidence and mortality of acute thoracic aortic dissection: Results from a whole nation study. Eur. J. Cardiothorac. Surg. 2016, 50, 1111-1117. [CrossRef]

23. Landenhed, M.; Engström, G.; Gottsäter, A.; Caulfield, M.P.; Hedblad, B.; Newton-Cheh, C.; Melander, O.; Smith, J.G. Risk profiles for aortic dissection and ruptured or surgically treated aneurysms: A prospective cohort study. J. Am. Heart Assoc. 2015, 4, e001513. [CrossRef]

24. Hagan, P.G.; Nienaber, C.A.; Isselbacher, E.M.; Bruckman, D.; Karavite, D.J.; Russman, P.L.; Evangelista, A.; Fattori, R.; Suzuki, T.; Oh, J.K.; et al. The International Registry of Acute Aortic Dissection (IRAD): New insights into an old disease. JAMA 2000, 283, 897-903. [CrossRef]

25. Pape, L.A.; Awais, M.; Woznicki, E.M.; Suzuki, T.; Trimarchi, S.; Evangelista, A.; Myrmel, T.; Larsen, M.; Harris, K.M.; Greason, K.; et al. Presentation, diagnosis, and outcomes of acute aortic dissection: 17-year trends from the International Registry of Acute Aortic Dissection. J. Am. Coll. Cardiol. 2015, 66, 350-358. [CrossRef]

26. Wang, D.J.; Fan, F.D.; Wang, Q.; Li, Q.G.; Zhou, Q.; Wu, Q.; Shi, G.F. Preliminary Characterization of Acute Aortic Dissection in the Mainland of China. Med. J. 2011, 124, 1726-1730.

27. Yamaguchi, T.; Nakai, M.; Sumita, Y.; Miyamoto, Y.; Matsuda, H.; Inoue, Y.; Yoshino, H.; Okita, Y.; Minatoya, K.; Ueda, Y.; et al. Current Status of the Management and Outcomes of Acute Aortic Dissection in Japan: Analyses of Nationwide Japanese Registry of All Cardiac and Vascular Diseases-Diagnostic Procedure Combination Data. Eur. Heart J. Acute Cardiovasc. Care 2019. [CrossRef]

28. Acosta, S.; Gottsäter, A. Stable population-based incidence of acute type A and B aortic dissection. Scand. Cardiovasc. J. 2019, 53, 274-279. [CrossRef]

29. Pacini, D.; Di Marco, L.; Fortuna, D.; Belotti, L.M.B.; Gabbieri, D.; Zussa, C.; Pigini, F.; Contini, A.; Barattoni, M.C.; De Palma, R.; et al. Acute aortic dissection: Epidemiology and outcomes. Int. J. Cardiol. 2013, 167, 2806-2812. [CrossRef]

30. Ante, M.; Mylonas, S.; Bischoff, M.; Rengier, F.; Brunkwall, J.; Bockler, D. Prevalence of the Computed Tomographic Morphological DISSECT Predictors in Uncomplicated Stanford Type B Aortic Dissection. Eur. J. Vasc. Endovasc. Surg. 2018, 56, 525-533. [CrossRef]

31. Mészáros, I.; Mórocz, J.; Szlávi, J.; Schmidt, J.; Tornóci, L.; Nagy, L.; Szép, L. Epidemiology and clinicopathology of aortic dissection. Chest 2000, 117, 1271-1278. [CrossRef]

32. McClure, R.S.; Brogly, S.B.; Lajkosz, K.; Payne, D.; Hall, S.F.; Johnson, A.P. Epidemiology and management of thoracic aortic dissections and thoracic aortic aneurysms in Ontario, Canada: A population-based study. J. Thorac. Cardiovasc. Surg. 2018, 155, 2254-2264. [CrossRef]

33. Li, Y.; Yang, N.; Duan, W.; Liu, S.; Yi, D. Acute aortic dissection in China. Am. J. Cardiol. 2012, 110, $1056-1061$. [CrossRef] [PubMed]

34. Xiong, J.; Chen, C.; Wu, Z.; Chen, D.; Guo, W. Recent evolution in use and effectiveness in mainland China of thoracic endovascular aortic repair of type B aortic dissection. Sci. Rep. 2017, 7, 17350. [CrossRef] [PubMed]

35. Wang, W.; Duan, W.; Xue, Y.; Wang, L.; Liu, J.; Yu, S.; Yi, D.; Registry of Aortic Dissection in China Sino-RAD Investigators. Clinical features of acute aortic dissection from the Registry of Aortic Dissection in China. J. Thorac. Cardiovasc. Surg. 2014, 148, 2995-3000. [CrossRef] [PubMed] 
36. Li, H.; Chan, Y.C.; Cheng, S.W. Contemporary endovascular treatment of type B aortic dissection in China. Asian Cardiovasc. Thorac. Ann. 2016, 24, 739-749. [CrossRef] [PubMed]

37. Xia, L.; Huang, L.; Feng, X.; Xiao, J.; Wei, X.; Yu, X. Chronobiological patterns of acute aortic dissection in central China. Heart 2020. [CrossRef] [PubMed]

38. Takeuchi, T.; Adachi, H.; Ohuchida, M.; Nakamura, T.; Satoh, A.; Jacobs, D.R.; Imaizumi, T. A case-control study found that low albumin and smoking were associated with aortic dissection. J. Clin. Epidemiol. 2004, 57, 386-391. [CrossRef]

39. Rylski, B.; Hoffmann, I.; Beyersdorf, F.; Suedkamp, M.; Siepe, M.; Nitsch, B.; Blettner, M.; Borger, M.A.; Weigang, E. Acute aortic dissection type A: Age-related management and outcomes reported in the German Registry for Acute Aortic Dissection Type A (GERAADA) of over 2000 patients. Ann. Surg. 2014, 259, 598-604. [CrossRef]

40. Takeuchi, S.; Yamaguchi, Y.; Soejima, K.; Yoshino, H. Incidence and characteristics of acute aortic dissection in patients with out-of-hospital cardiopulmonary arrest evaluated by non-contrast computed tomography. Eur. Heart J. Acute Cardiovasc. Care 2020. [CrossRef]

41. Chen, Y.; Zhang, S.; Liu, L.; Lu, Q.; Zhang, T.; Jing, T. Retrograde Type A Aortic Dissection after Thoracic Endovascular Aortic Repair: A Systematic Review and Meta-Analysis. J. Am. Heart Assoc. 2017, 6, e004649. [CrossRef]

42. Hossack, M.; Patel, S.; Gambardella, I.; Neequaye, S.; Antoniou, G.A.; Torella, F. Endovascular vs. Medical Management for Uncomplicated Acute and Sub-acute Type B Aortic Dissection: A Meta-analysis. JVEVS 2020, 59, 794-807. [CrossRef]

43. Zhao, X.; Chen, J.; Cui, Y.; Wu, F.; Hu, D. Current status of primary hypertension in China: An epidemiological study of 12 provinces, 1 autonomous region and 1 municipality. Natl. Med. J. China 2006, 86, 1148-1152.

44. World Health Organisation: Prevalence of Tobacco Smoking. Available online: http://gamapserver.who.int/ gho/interactive_charts/tobacco/use/atlas.html (accessed on 15 October 2020).

45. Herrett, E.; Shah, A.D.; Boggon, R.; Denaxas, S.; Smeeth, L.; van Staa, T.; Timmis, A.; Hemingway, H. Completeness and diagnostic validity of recording acute myocardial infarction events in primary care, hospital care, disease registry, and national mortality records: Cohort study. BMJ 2013, 346, f2350. [CrossRef]

46. Bright, R.A.; Avorn, J.; Everitt, D.E. Medicaid data as a resource for epidemiologic studies: Strengths and limitations. J. Clin. Epidemiol. 1989, 42, 937-945. [CrossRef]

47. Schneeweiss, S.; Avorn, J. A review of uses of health care utilization databases for epidemiologic research on therapeutics. J. Clin. Epidemiol. 2005, 58, 323-337. [CrossRef] [PubMed]

48. Banerjee, A.; Begaj, I.; Thorne, S. Aortic dissection in pregnancy in England: An incidence study using linked national databases. BMJ Open 2015, 5, e008318. [CrossRef] [PubMed]

49. Erbel, R.; Aboyans, V.; Boileau, C.; Bossone, E.; Bartolomeo, R.; Eggebrecht, H.; Evangelista, A.; Falk, V.; Frank, H.; Gaemperli, O.; et al. 2014 ESC Guidelines on the diagnosis and treatment of aortic diseases. Document covering acute and chronic aortic diseases of the thoracic and abdominal aorta of the adult. The Task Force for the Diagnosis and Treatment of Aortic Diseases of the European Society of Cardiology (ESC). Eur. Heart J. 2015, 36, 2779-2926. [PubMed]

Publisher's Note: MDPI stays neutral with regard to jurisdictional claims in published maps and institutional affiliations.

(C) 2020 by the author. Licensee MDPI, Basel, Switzerland. This article is an open access article distributed under the terms and conditions of the Creative Commons Attribution (CC BY) license (http://creativecommons.org/licenses/by/4.0/). 